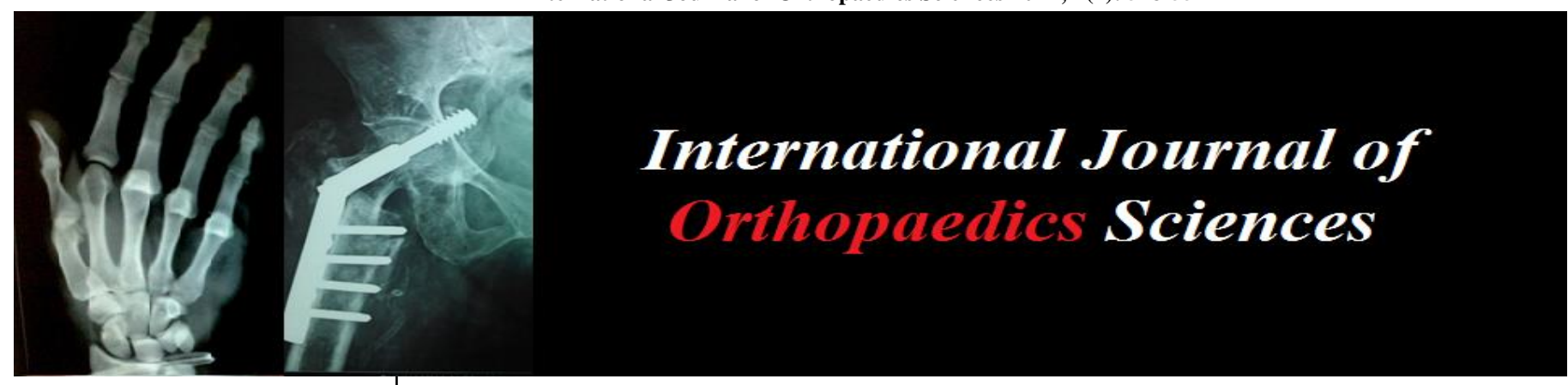

E-ISSN: 2395-1958

P-ISSN: 2706-6630

IJOS 2021; 7(1): 548-552

(C) 2021 IJOS

www.orthopaper.com

Received: 23-11-2020

Accepted: 25-12-2020

\section{Dr. Buggaveeti Goutham} Senior Resident, Orthopedics, Guntur Medical College and Hospital. NTR University of Health Sciences, Vijayawada, Kannavaarithota $4^{\text {th }}$ Lane,

Guntur, Andhra Pradesh, India

Dr. Madhukar Reddy Vanga Assistant Professor, Orthopedics Guntur Medical College and Hospital, Om Sai Nivas Apartments, Pattabhipuram 1 ${ }^{\text {st }}$ Lane, Guntur, Andhra Pradesh, India

Dr. Sivaram Sidda

Senior Resident Orthopaedics, Guntur Medical College Andhra Pradesh, India
Corresponding Author: Dr. Madhukar Reddy Vanga Assistant Professor, Orthopedics Guntur Medical College and Hospital, Om Sai Nivas Apartments, Pattabhipuram $1^{\text {st }}$ Lane, Guntur, Andhra Pradesh, India

\section{The effect of body mass index on functional outcome in total knee replacement}

\author{
Dr. Buggaveeti Goutham, Dr. Madhukar Reddy Vanga and Dr. Sivaram \\ Sidda
}

DOI: https://doi.org/10.22271/ortho.2021.v7.i1i.2540

\section{Abstract}

Background: Osteoarthritis is one of the leading causes of disability. TKR is the most common procedure for end stage arthritis. Although obesity is assumed to bring out a negative influence on survival of TKR, there is no definitive proof in literature. The impact of obesity on the outcomes of TKA is still debated.

Aim: To investigate the effects of body mass index on the rehabilitation process in patients with a recent TKR.

Design: This prospective study included patients $(\mathrm{N}=50)$ who underwent TKR between 2018 and 2019 for primary OA.

Materials and Methods: Patients undergoing TKR were identified from a prospective arthroplasty database. 50 patients were included in the study. Age, gender, BMI, pre- and post-operative functional scores [International knee society score: KSS], complications were recorded. WHO BMI classification was used to group the patients. The functional outcome of the normal weight group $(B M I<25)$ was compared to the overweight and obese group (BMI $\geq 25)$.

Results: Mean age in the study was 65.8 (52-78). 60\% (30) were female. The mean BMI was 28.8 (1852). $70 \%$ of patients were either overweight or obese. Mean follow-up was 12.33 mo (6-24 mo). No significant difference was identified in pre or post-operative KSS in normal weight $(B M I<25)$ group compared with that of patients with a $\mathrm{BMI} \geq 25$. Overall, there was 1 case of infection $(2 \%)$, with no complications or revisions in the normal weight group $(\mathrm{BMI}<25)$

Conclusion: BMI did not show any influence on post-operative outcome comparing normal weight individuals and the ones with BMI > 25. Patients should not be denied total knee replacement based solely on BMI alone.

Keywords: Total knee replacement, body mass index, total knee arthroplasty, osteoarthritis.

\section{Introduction}

Knee osteoarthritis (OA) is one of the leading causes of disability and it affects over 250 million people worldwide ${ }^{[1]}$. Joint arthroplasty for knee is one of the most common elective and cost-effective surgical intervention for end stage lower-limb arthritis ${ }^{[1]}$. Occurring in company with this increase in demand is the exponential increase in obesity in society ${ }^{[2]}$. It is well known that obesity increases the risk of a number of medical conditions like diabetes, ischaemic heart disease and stroke ${ }^{[3]}$. It is also shown that obesity is an independent risk factor for development of knee osteoarthritis ${ }^{[4]}$. Obesity has a number of implications for surgery in general, but in particular for elective surgery such as TKA, obesity is an independent risk factor for a number of complications including wound infection, acute coronary syndrome and UTI ${ }^{[5]}$. Although obesity is assumed to bring out a negative influence on survival of TKR, there is no definitive proof in literature. The impact of obesity on the outcomes of TKA is still debated. A systematic review of the literature ${ }^{[6]}$ showed that deep infection and revision for any reason were more often in obese patients than in non-obese patients, but another recent systematic review ${ }^{[7]}$ found that overall obese patients did not have significantly lower knee scores. The aim of the study was to assess the effect of (BMI) on functional outcome following primary total knee arthroplasty. 


\section{Materials and Methods}

- Data was compiled during a 2-year period from November 2017 through November 2019 from consecutive patients who underwent TKA for primary Osteoarthritis. A total of 50 patients were included in the study. Pre operatively body mass index (BMI) was calculated for each patient using the standardized formula; weight in kilograms squared, divided by height in meters squared. International knee society scores were collected pre and post-operatively at 6, 12 and 24 month intervals. Complications included one case of deep infection requiring subsequent revision.

- Patients were divided into two groups for the purpose of the study, those with a normal BMI (less than or equal to 25 ) in Group 1 and those who were overweight or obese (greater than 25) in Group 2 according to the WHO BMI classification ${ }^{[8]}$. A sub-group analysis was also performed comparing all five WHO BMI groups namely normal weight, overweight, class 1 obese, class 2 obese and class 3 obese.

- The primary outcomes assessed were pre-operative and 1year post-operative KSS. Originally published in 1989 in Clinical Orthopaedics and Related Research, the Knee Society Clinical Rating System (KSS) was designed to provide a simple and objective scoring system to assess the knee and patient's functional abilities before and after total knee arthroplasty. ${ }^{[9]}$

- The original KSS has two sections namely "Knee Score" (7 items) and "Functional Score" (3 items). Both are scored from 0 to 100 with knee conditions improving from lower to higher scores.

\section{Statistical Analysis}

- All the data was collated on a Microsoft Excel spreadsheet. Results were analysed and were presented as percentage, mean and standard deviation for each BMI group. Statistical significance was assessed between the study groups using the student $\mathrm{t}$ test, with significance set at $P<0.01$.

- A further sub-group analysis was performed comparing each of the WHO BMI sub-groups with significance set at $p<0.01$.

Table 1: BMI Classification

\begin{tabular}{|c|c|}
\hline \multicolumn{2}{|c|}{ Who BMI Classification } \\
\hline Under- Weight & $<18.5$ \\
\hline Normal & $18.5-24.9$ \\
\hline Over Weight & $25-29.9$ \\
\hline
\end{tabular}

\begin{tabular}{|c|c|}
\hline Obese-I & $30-34.9$ \\
\hline Obese-II & $35-39.9$ \\
\hline Obese-III & $\geq 40$ \\
\hline
\end{tabular}

Table 2: International Knee Society Scoring

\begin{tabular}{|c|c|}
\hline Part 1 : Knee Score & Part 2 : Functional Score \\
\hline 1.Pain & 1. Walking $(1$ Block $=$ \\
\hline None- 50 & 100MTS) \\
\hline MILD/OCASSIONAL- 45 & Unlimited: 50 \\
\hline MILD (Walking and Stairs)- 30 & >10 Blocks: 40 \\
\hline Moderate (Ocassional)- 20 & 5-10 Blocks: 30 \\
\hline Moderate (Continual)- 10 & $<5$ Blocks: 20 \\
\hline Severe- 0 & House Bound: 10 \\
\hline & Unable: 0 \\
\hline \multicolumn{2}{|c|}{ 2. Range of Motion -1 Point for Every 5 Degrees } \\
\hline 3. Stability & 2.Stairs \\
\hline a) Anterio-Posterior & Normal up and Down: 50 \\
\hline$<5 \mathrm{MM}-10$ & Normal up and Down With \\
\hline $5-10 \mathrm{MM}-5$ & Rail Support:40 \\
\hline$>10 \mathrm{MM}-0$ & Up and Down With The \\
\hline b) Medio -Lateral & Support of Rail: 30 \\
\hline$<5$ Degrees: - 15 & Up With Support of Rail \\
\hline 6-9 Degrees: 10 & Unable to Climb Down: 15 \\
\hline 10-14 Degrees: 5 & Unable: 0 \\
\hline 4. Flexion Contracture & 3.Walking aid used \\
\hline 5-10 Degrees: -2 & None: 0 \\
\hline 10-15 Dgerees: -5 & Cane/Stick: -5 \\
\hline 16-20 Degrees: -10 & Two Sticks/Cane: -10 \\
\hline$>20$ Degrees: -15 & Crutch: -15 \\
\hline \multicolumn{2}{|l|}{ 5. Extensor LAG } \\
\hline \multicolumn{2}{|l|}{$<10$ Degrees: -5} \\
\hline \multicolumn{2}{|l|}{ 10-20 Degrees: -10} \\
\hline \multicolumn{2}{|l|}{$>20$ Degrees: -15} \\
\hline 6.Alignment (Varus /Valgus) & Grading \\
\hline 5-10 Degrees: 0 & Excellent: $80-100$ \\
\hline 0-4 Degrees: 3 Points FOR & Good: $70-19$ \\
\hline EACH Degree & Fair: $60-69$ \\
\hline $\begin{array}{l}\text { 10-15 degrees: } 3 \text { Points for } \\
\text { Each Degree }\end{array}$ & Poor: $<60$ \\
\hline
\end{tabular}

\section{Results}

- A total of 50 primary total knee replacements were performed in the institution between 2017 and 2019. The mean age was 65.8 years (52-78), with $40 \%$ Male and $60 \%$ Female. The mean follow-up was 12.3 months, with a range of 6 mo to 2 years. The distribution according to BMI group is shown in Figure1. The mean BMI was 28.8 (18-52) with $30 \%$ obese, $40 \%$ overweight and $30 \%$ normal weight. The two comparative study groups consisted of Group 1 ( $n=15$ patients) and Group 2 ( $n=$ 35 patients).

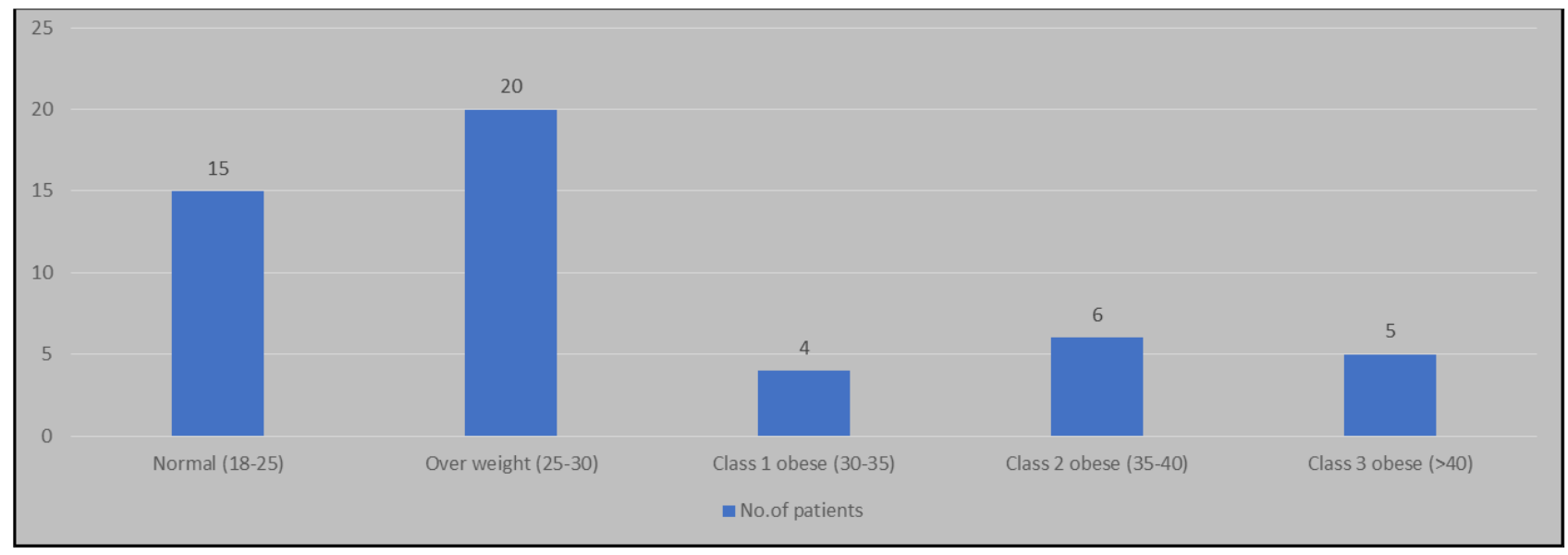

Fig 1: Distribution according to BMI group 


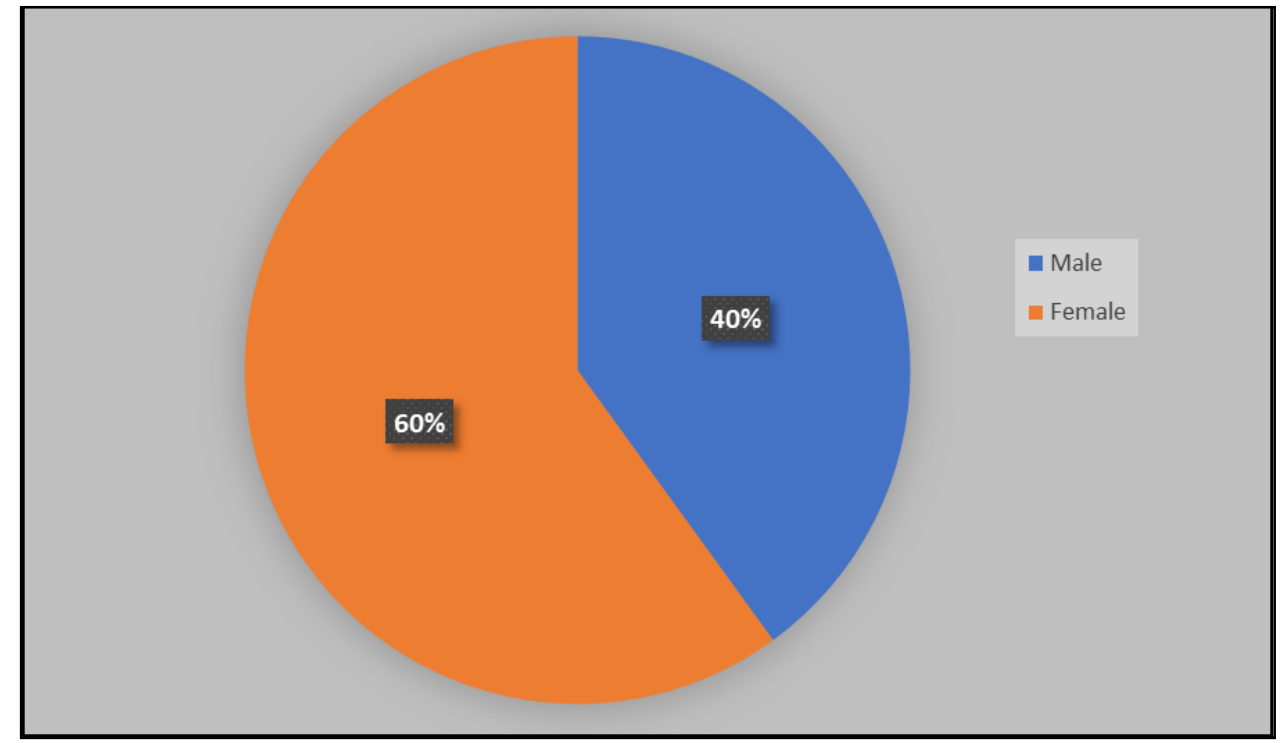

Fig 2: Sex Distribution

\section{Functional Outcome}

There was no significant difference in the pre-op scores between Group 1; 56.4 (48-56) and Group 2; 52.6 (32- 52) (P $=0.05)$. Similarly, there was no significant difference in the post op scores between the two groups, 88.6 (82-94) and 82.5 (72-86) $(P=0.05)$ respectively. The complete functional outcome scores are presented in Tables 3 and 4

Table 3: Pre and post-operative functional scores

\begin{tabular}{|c|c|c|}
\hline Functional Score & Group 1 (BMI < 25) & Group 2 (BMI>25) \\
\hline Pre-operative & 56.4 & 52.6 \\
\hline 1-year post-operative & 88.6 & 82.5 \\
\hline
\end{tabular}

Table 4: Sub group analysis of post-operative knee society scores

\begin{tabular}{|c|c|}
\hline BMI & 1-year postoperative Functional Score \\
\hline Normal & 88.6 \\
\hline Over weight & 86.2 \\
\hline Class 1 obese & 84.8 \\
\hline Class 2 obese & 80.4 \\
\hline Class 3 obese & 78.6 \\
\hline
\end{tabular}

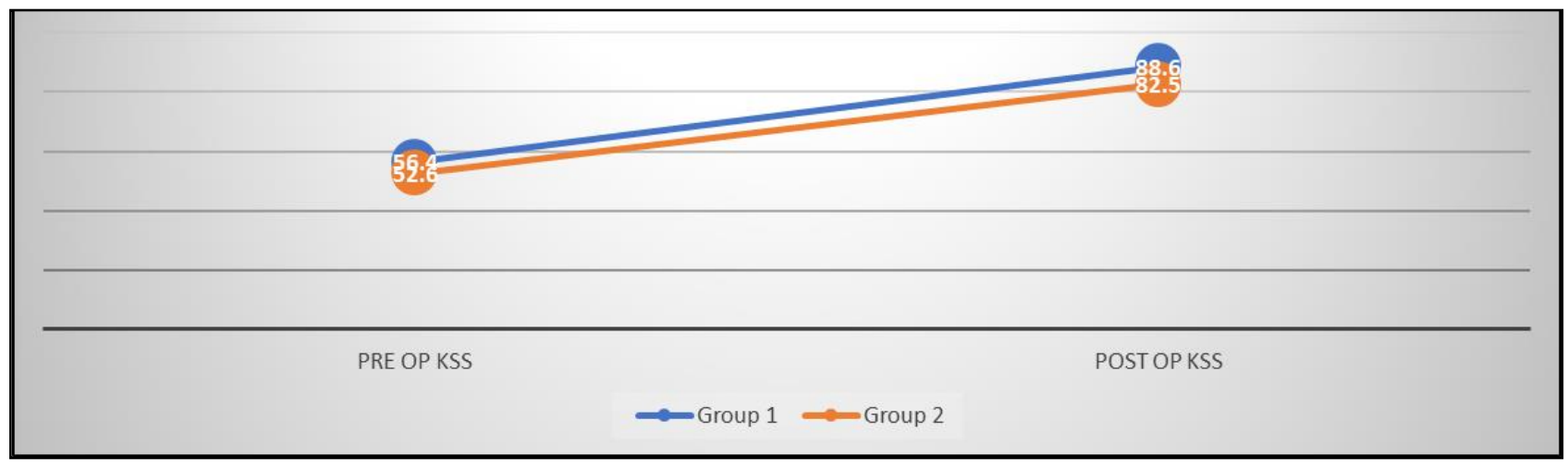

Fig 3: Comparision of Pre and Post op functional scores 


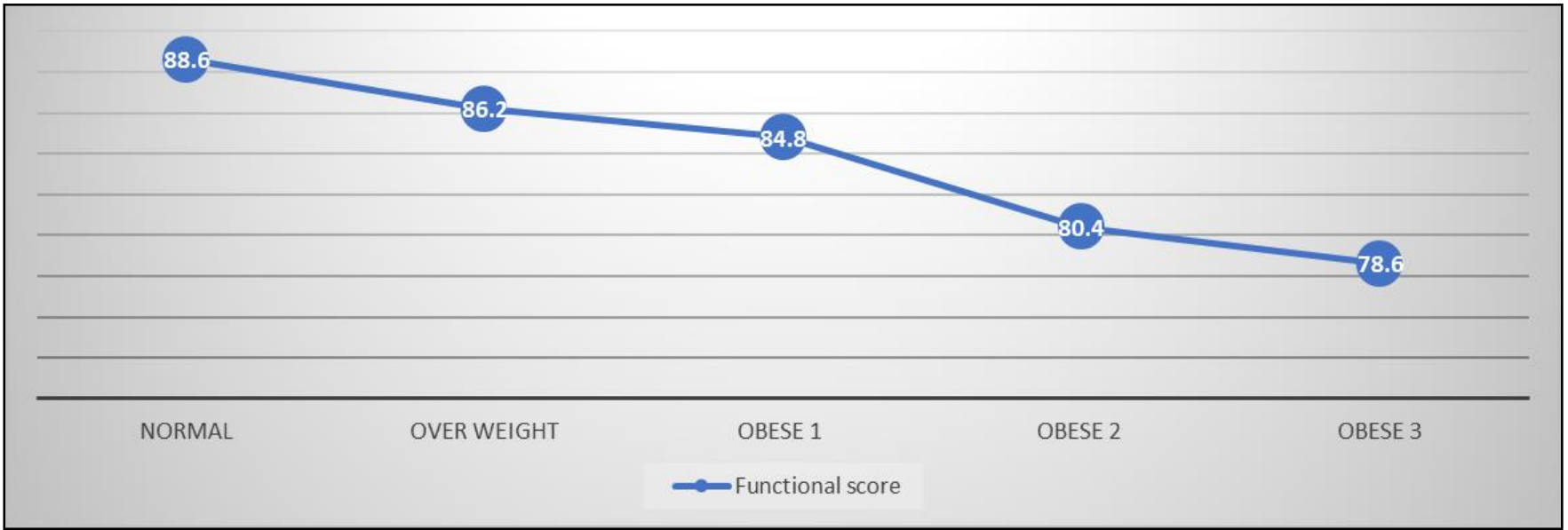

Fig 4: Functional score based on BMI

\section{Complications}

- While there were no complications in group 1, there was a single episode of infection for which revision was done subsequently for the patient belonging to class 2 obese group.

- The absolute number of complications were not sufficient to perform any statistical analysis.

\section{Discussion}

- Overall, in the study it was revealed that there is no significant difference in post-operative functional outcome in patients with a normal BMI as compared to overweight or obese patients. A sub-group analysis found lower functional outcome scores in class 2 and class 3 obese patients compared to both overweight and class 1 obese patient.

- The study shows that, most of the patients presenting for total knee replacement are either overweight or obese. This finding is also observed in previous studies, which revealed a considerable proportion of patients undergoing total knee arthroplasty are now obese ${ }^{[10]}$.

- A recent study by baker et al. ${ }^{[11]}$ using NJR data on 13673 primary TKRs revealed equivalent functional outcome comparing normal weight individuals and the ones with BMI > 25, a similar finding in this study. They found that irrespective of BMI, the improvement of patient reported outcomes (PROMs) were similar.

- Similarly, it was revealed by Desmukh et al. ${ }^{[12]}$ that there is no correlation with BMI and functional outcome at 1year follow-up.

- However, a consensus is yet to be reached, as there is also evidence showing inferior clinical outcomes in increasing BMI particularly more than 40 . A review on 445 total knee replacements was done by Collins et al. ${ }^{[16]}$ which showed inferior outcome in individuals with a BMI more than 30 on a follow-up of 9 years.

- Interestingly, although over weight and obese patients showed lower outcome scores as compared to non-obese patients, they achieved a significant absolute functional improvement and the authors concluded that "No reason is found to limit access to total knee replacement in obese patients".

- Despite no difference in functional outcome, there was an episode of infection in obese group. Literature showed clear evidence of increased peri-operative complications with increasing BMI in TKA. The etiology behind this is multifactorial. The risk of both superficial and deep periprosthetic joint infections is significantly high with increasing BMI. A recent meta-analysis by Kerkhoffs et al. ${ }^{[13]}$ on 15276 obese and 5061 non obese patients revealed an odds ratio of 1.9 for all infection and 2.38 for deep infection in obese patients as compared to nonobese patients.

- The risk of thromboembolic phenomenon is also high in obese patients ${ }^{[14]}$. Counselling the patients in detail about the increased risk of peri-operative complications with increasing BMI is also crucial. While it would seem intuitive that patients should attempt to lose weight before surgery, some recent evidence also suggests that obese patients losing a significant proportion of bodyweight preoperatively, actually have a higher rate of surgical site infection compared to control ${ }^{[15]}$. The subject of perioperative weight management needs further research.

- It is acknowledged that long term outcome may not correspond to early functional outcome and this subject requires a further research.

\section{Conclusion}

In conclusion, overall in our study it is shown that comparing normal weight individuals and those with BMI $>25$ there is no difference in post-operative functional outcome. Patients should receive a detailed counselling regarding the potential increased risk of complications with increasing BMI, however TKA should not be denied based solely on weight if medically fit to undergo the procedure.

\section{References}

1. Felson D, Naimark A, Anderson J, Kazis L, Castelli W et $a l$. The prevalence of knee osteoarthritis in the elderly. The Framingham osteoarthritis study. Arthritis Rheum 1987;30:914-918.

2. Kerkhoffs GMMJ, Servien E, Morgan KMH, Watson D, Perry I, Barry M et al. Dublin: Department of Health and Children; SLAN 2007 Survey of lifestyle attitudes and nutrition in Ireland. Main Report, 2007.

3. Bray GA. Overweight is risking fate. Definition, classification, prevalence, and risks. Ann N Y Acad Sci 1987;499:14-28.

4. Felson DT, Anderson JJ, Naimark A, Walker AM, Meenan RF. Obesity and knee osteoarthritis. The Framingham Study. Ann Intern Med 1988;109:18-24.

5. Bamgbade OA, Rutter TW, Nafiu OO, Dorje P. Postoperative complications in obese and nonobese patients. World J Surg 2007;31:556-560.561.

6. Dunn W, Dahm D, Bramer JA et al. The Influence of 
Obesity on the Complication Rate and Outcome of Total Knee Arthroplasty. J Bone Joint Surg Am 2012;94:18391844.7.

7. McElroy M, Pivec R, Issa K, Harwin S, Mont M. The Effects of Obesity and Morbid Obesity on Outcomes in TKA. J Knee Surg 2013;26:83-88.

8. WHO. Geneva: World Health Organization; Global database on Body Mass Index: BMI Classification, 2006.

9. Insall John, N.; Dorr, Lawrence D, Scott Richard D, Norman W Scott. Rationale of the knee society rating system. Clinical Orthopaedics and Related Research: November 1989;248:13-14.

10. Kremers HM, Visscher SL, Kremers WK, Naessens JM, Lewallen DG. The effect of obesity on direct medical costs in total knee arthroplasty. J Bone Joint Surg Am 2014;96:718-724.

11. Baker P, Petheram T, Jameson S, Reed M, Gregg P, Deehan $\mathrm{D}$. The association between body mass index and the outcomes of total knee arthroplasty. J Bone Joint Surg Am 2012;94:1501-1508.

12. Deshmukh RG, Hayes JH, Pinder IM. Does body weight influence outcome after total knee arthroplasty? A 1-year analysis. J Arthroplasty 2002;17:315-319.

13. Kerkhoffs GM, Servien E, Dunn W, Dahm D, Bramer JA, Haverkamp D. The influence of obesity on the complication rate and outcome of total knee arthroplasty: a meta-analysis and systematic literature review. J Bone Joint Surg Am 2012;94:1839-1844.

14. Mantilla CB, Horlocker TT, Schroeder DR. Risk factors for clinically relevant pulmonary embolism and deep venous thrombosis in patients undergoing primary hip or knee arthroplasty. Anesthesiology 2003;99:552-560.

15. Inacio MC, Kritz-Silverstein D, Raman R, Macera CA, Nichols JF, Shaffer RA et al. The risk of surgical site infection and re-admission in obese patients undergoing total joint replacement who lose weight before surgery and keep it off post-operatively. Bone Joint J 2014;96B:629-635.

16. Collins RA, Walmsley PJ, Amin AK, Brenkel IJ, Clayton RA. Does obesity influence clinical outcome at nine years following total knee replacement J Bone Joint Surg Br 2012;94:1351-1355. 